\title{
Evaluating Impact of Land-Use/Land-Cover Change on Surface Runoff using Arc SWAT Model in Sore and Geba Watershed, Ethiopia
}

\author{
Temesgen Mekuriaw \\ Lecturer, Department of Hydraulic and Water Resources, Debre Tabor University, Debre Tabor, Ethiopia
}

\begin{abstract}
The aim of this study is to assess the impact of LULC change on surface runoff in the watershed of Sore and Geba, the upper Baro-river basin covering an area of approximately $6551 \mathrm{~km}^{2}$ in Ethiopia. Landsat images were used to analyze the LULC change trends for the periods of three decades (1987-2017). LULC map of the area produced using the maximum likelihood algorithms based supervised image classification. Trends in LULC change showed that farm land has augmented by $16.55 \%$ within the periods of between 1987 and 2017 with annual expansion by $36.15 \mathrm{~km}^{2}$ at the expense of other land use types such as open forest, dense forest and wood land. The Soil and Water Assessment Tool (SWAT) model has been used to evaluate the impacts of LULC change on surface runoff. Nine sensitive flow control parameters were identified and used for calibration of the model. In both calibration and validation periods, good performance was obtained. Results show between 1987 and 2017, a 16.5\% cultivated land expansion was observed which may explain an increase of about $6.65 \mathrm{~m}^{3} / \mathrm{s}(32 \mathrm{~mm})$ in annual surface runoff. In general, during the study period significant influence of LULC change were reflected in changes to the hydrologic system of the region with an important management implication for this region as well as other similar regions in Ethiopia.
\end{abstract}

Keywords: Land use change, Sore and Geba watershed, Surface runoff, SWAT

DOI: $10.7176 / \mathrm{JEES} / 9-10-02$

Publication date:October $31^{\text {st }} 2019$

\section{INTRODUCTION}

Water is an indispensable for living and non-living environment. The quality and the available amount of water in relation to human needs and population growth are still limited. Land and water resource management is a key issue to maintain the sustainability of natural resources and satisfy the current demands of population. Sustainable land use planning has a close link with water bodies as changes in lan use pattern has an effect on water resource through the relevant process of the hydrological cycle (Guo et al., 2008; Zhang L., 2016; Santosh M. et al., 2018; Birhanu A, 2019). The availability of water in a given area depends on how the precipitation of the area is separated from different elements of the hydrologic cycle such as groundwater recharge, interflow, evaporation, surface runoff. Hence, a change in land use and land cover of the area can modify the magnitudes of those elements, have consequences change in natural environment. Recent research suggests that there has been a substantial variation in LULC in the past few decades over many parts of the globe (Lindquist et al., 2012; Bao-qi Li, 2018; Santosh M. et al., 2018; Asirat T., 2019; Ebrahim H. \& Mohamed A. 2018). In Ethiopia, a decline in natural flora refuges such as forests and shrubs together with an increase in cultivated and bare lands causes increase in surface runoff and soil erosion from the catchment (Gessesse et al., 2014;Tarekegn A., 2017; Emnet N. et al., 2019). In highland parts areas, rapid extension of farmlands towards natural forests and vegetation has deepened the problem of land squalor, particularly through soil degradation by water (Bewket and Abebe, 2013; Santosh M. et al., 2018; Kondoh A. 2018; Birhanu A, 2019).

The natural resources of Baro river basin in southwestern Ethiopia is under continued change because of LULC change starting from since 1986 due to relocation, increase in inhabitants, over exploitation of resources and development of commercial farming (Tilahun, 2015). The downstream human settlement and agricultural lands are seriously affected by unusual occurrences of floods overflowing riverbanks beyond the normal flooded zones (Woube, 1999). Surface runoff is a significant factor affecting the development and progress of floods, soil erosion and other hydrological hazards. The runoff characteristics of a drainage basin is influenced in a large extent by a LULC change, which in turn affects the availability of ground and surface of the watershed, which leads to additional change in LULC (Getahun and Haj, 2015; Sajikumar and Remya, 2015).

Baro-Akobo river basin, which is found in Southwestern parts of Ethiopia, is one of the areas, which is rich in diversified natural resource and a habitat for different peoples with different working culture and farming practices (Alemayehu, 2016; Kassa et al., 2016). The increasing population coupled with the expansion of cereal cropping practices, resettlement and commercial farming like Palm oil, tea, and coffee plantation is one of the threats to deteriorate the original natural forest cover, the traditional farming practices, and livelihood of the community living in that region. Quantifying and evaluating the influences of LULC change on hydrological components will help in identifying the causes of flood and its implication on the watershed. To apply a corrective 
source-based measure for the problem and develop a new plan in the catchment, evaluating the effects of land use practice on hydrology is imperative step in making a better decision about the land use planning by the government and the decision makers.

The aim of this research is to assess land use change impacts on surface runoff using Soil and Water Assessment Tool (SWAT) model. Specifically,

$>$ understanding the effects of different land use practices on surface runoff response and identifying land cover change trends in the area

$>$ determining the components of water balance in the watershed, and

$>$ understanding implications and recommend a land use management best practice

\section{METHODOLOGY}

\subsection{Description of study area}

Baro river is one of the major rivers in Baro-Akobo basin which lies in southwestern part of Ethiopia located between $33^{\circ} 23^{\prime} 39^{\prime \prime}$ to $36^{\circ} 18^{\prime} 21^{\prime}$ 'E and $9^{0} 25^{\prime}$ ' $2^{\prime \prime}$ to $7^{0} 27^{\prime} 8^{\prime}$ 'N , which defines part of Ethiopia border with South Sudan. From its source in the southwestern Ethiopian highlands it flows west for 306 kilometers to join the Pibor River that flows to White Nile after forming Sobat River system. Regionally it lies in the Ethiopian administrative regions of Gambela, Oromia and Southern Nation Peoples regional state. The drainage area of the basin including its tributaries are about $41,400 \mathrm{~km}^{2}$ and is bordered by the Sudan in the Northwest, Abbay Basin in the east and Akobo basin in the Southwest. The elevation of the catchment ranges from $3244 \mathrm{~m}$ in the Southwestern highlands of Ethiopia and $390 \mathrm{~m}$ at the point where the border of South Sudan. For this specific study, Sore and Geba watershed about $6551.07 \mathrm{~km}^{2}$ which is sub watershed of Baro river basin (one of the main tributaries) was selected (Figure 1). The elevation of Sore and Geba watershed ranges from 937 to 3001 meter above sea level.

Depending on the altitude and temperature of the area, the climate of Sore and Geba watershed categorized under the warm to cool, semi humid zones. The average annual rainfall of Sore and Geba watershed varies from $1533 \mathrm{~mm}$ up to $2046 \mathrm{~mm}$. The rainfall distribution pattern of the study area is experiencing a unimodal rainfall pattern with continuous highest rain from March to October. The land use types of Sore and Geba watershed is predominantly broad leaf montane forest, wood land, cultivated land and water bodies (Wubie, 2015).
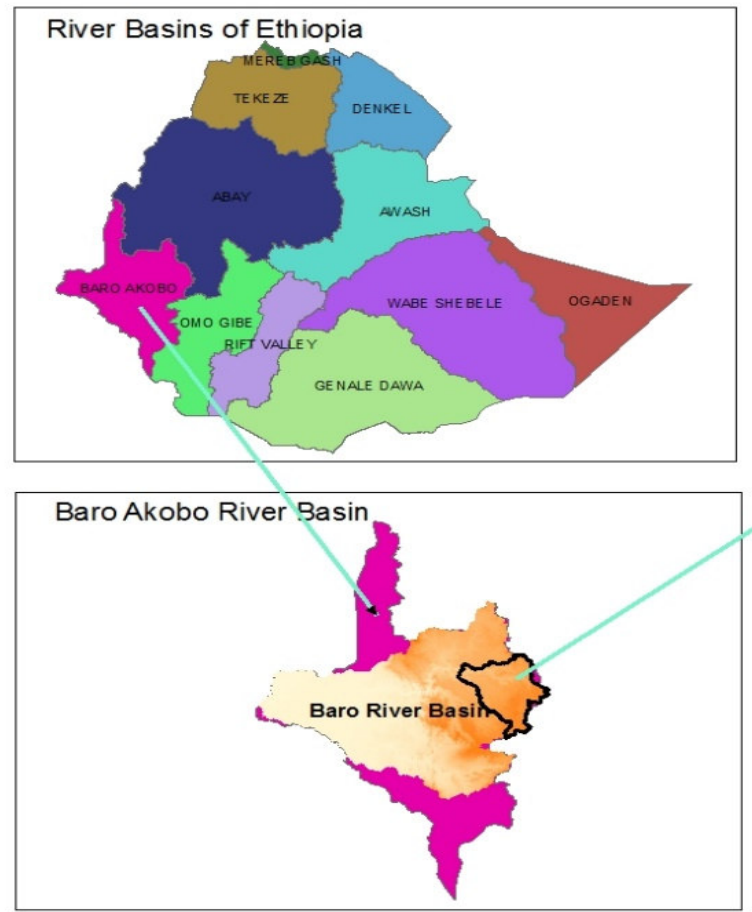

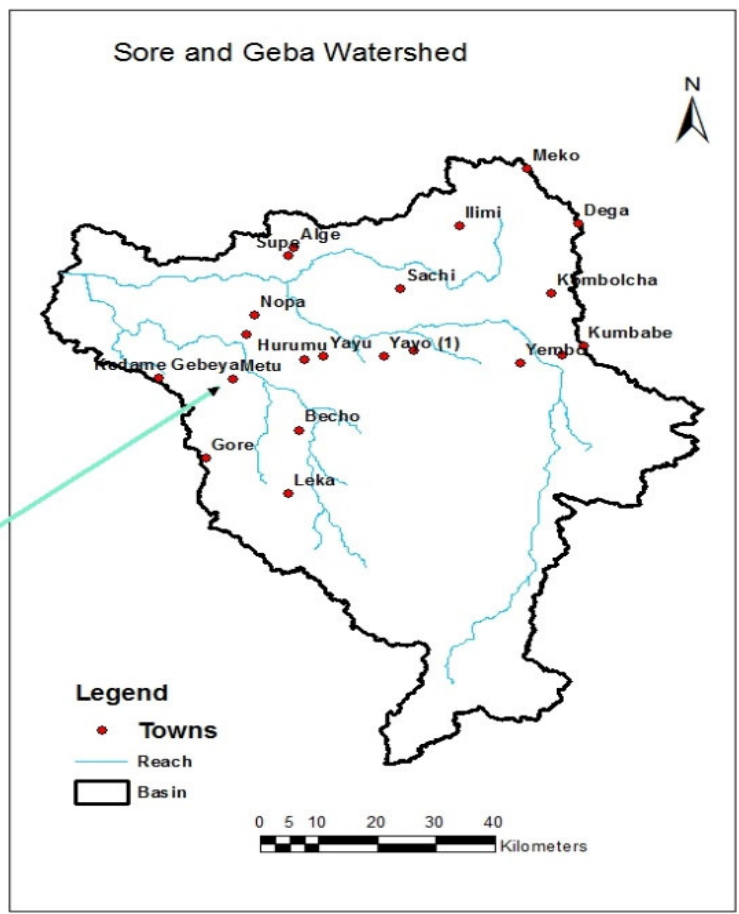

Figure 1. Location map of the study area

\subsection{Data}

For this study, different climatic and topographic data were acquired such as DEM, LULC and hydrological data. The land cover satellite image and DEM were obtained from United State Geological Survey (USGS) website. The climatological data can be gained from NMA of Ethiopia. Hydrological and Soil data was obtained from Ethiopian MoWIE and FAO. Satellite imageries of different bands for each year were used to identify the LULC change spreading in Sore and Geba watershed in the last 30 years. Landsat-5-TM, Landsat-7-ETM+ and Landsat 
8 can be used for the year 1987, 2001 and 2017 correspondingly.

\subsection{Methods}

Depending on the input data need and its availability, surface runoff and peak flow of the given watershed can be estimated using different empirical formulas and hydrological models such as SWAT and WEAP. SWAT is widely used and is the most applicable software for the study area. Because of the successful application of SWAT model for assessment of impact of land use on water resources, in this study, together with a GIS application, SWAT software was used. Generally, workflow framework is shown in (Figure 2).

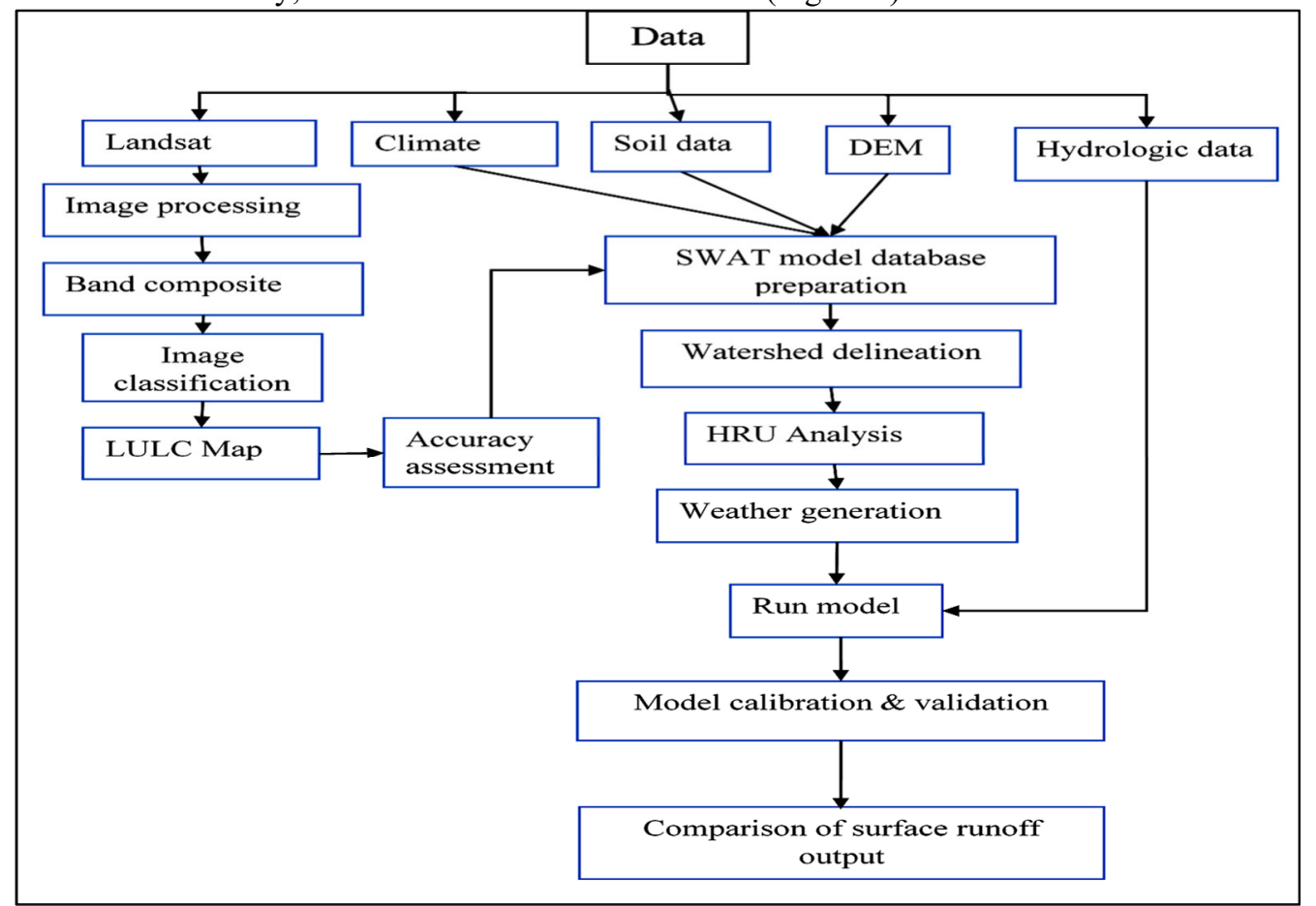

Figure 2. Framework of the study

\section{Image processing}

The selection of the acquired data date was made as much as possible within the same annual season to avoid a seasonal variation in vegetation pattern and distribution throughout the year. The images were georeferenced to UTM projection UTM zone 37N. All satellite images are composite to the composition of RGB colors.

Table 1. Description of data

\begin{tabular}{lcccc}
\hline \multicolumn{1}{c}{ Data } & Sources & \multicolumn{1}{c}{ Path/Row } & Acquisition Dates & Resolution (M) \\
\hline Landsat-5-TM & USGS & $170 / 054$ & $1987-01-22$ & 30 \\
Landsat-7-ETM+ & USGS & $170 / 055$ & & \\
& & $170 / 054$ & $2001-02-05$ & 30 \\
Landsat 8 & USGS & $170 / 055$ & $2017-02-04$ & 30 \\
& & $170 / 055$ & & \\
\hline
\end{tabular}

There are several image classification techniques exist in literature for remote sensing image classification. Broadly categorized as supervised or unsupervised image classification techniques. The most widely used and found to be accurate method is supervised image classification techniques (Hasmadi, et. al. 2009). For this study, by selecting training sites and generating signature files, supervised image classification techniques was applied to classify the image using a maximum likelihood classification algorithm. Image classification was done by using ArcGIS image processing tools.

\section{LULC mapping}

The LULC classes of Sore and Geba watershed has been differentiated and identified depending on the available sources such as, the prior local knowledge of the study area, remote sensing, google satellite image and previous research output of the study area. The Landsat images can be classified into five different types of LULC classes.

1) Cultivated land: Areas used for annual crops by rainfed agriculture, Cereal Land Cover system which is moderately stocked and scattered rural settlements that are closely associated to cultivated fields. Scattered settlements were difficult to separate from remotely sensed images, due to the fact that it combined under the categories of cultivated land during classification 
2) Dense forest: Forest montane, broadleaf, dense (50-80\% crown cover) which includes evergreen forest land

3) Open forest: Forest montane, broadleaf, open (20-50\% crown cover) which includes vegetation's with trees

4) Wood land: Areas with bushes, open (20-50\% tree cover) mixed with some grasses, and

5) Water bodies: Marsh lands, Rivers and its main tributaries.

\section{Accuracy assessment}

Quality analysis was done by the confusion matrix. The various parameters describing the quality of image classifications are derived from the confusion matrix. The confusion matrix is a table with rows which represented the mapped (classified) categories derived from remote sensing data and the columns which representing the reference (observed) classes (Olofsson et al., 2014). The most frequently used index is overall accuracy, accuracy of the producer, and accuracy of the user. The resulting error matrix was used to calculate these.

Overall accuracy shows the percentage of pixels properly classified. This measure can be calculated by the total number of pixels in the confusion matrix as the ratio of the total number of accurately classified pixels (diagonals).

The accuracy of the producer is calculated by dividing the number of correct pixels by the total number of pixels as derived from the reference data into one class. It is an error of omission (exclusion). The accuracy of the user is derived from the ratio of the number of pixels in each category correctly classified to the total number of pixels in that category. It describes error of commission (inclusion).

The Kappa coefficient $(\mathrm{K})$ is another accuracy assessment statistic used for this study. It reflects the difference that is expected by chance between the actual agreement and the agreement. It can be calculated by the following equation.

$$
\widehat{K}=\frac{(\text { total } * \text { sum of correct })-\text { sum of all the }(\text { row total } * \text { column total })}{\text { total squared }- \text { sum of all the }(\text { row total } * \text { column total })}
$$

The value of kappa ranges between 0 and 1, where 0 represents agreement due to chance only and a value of 1 represents complete agreement between the two data sets (classified map and reference data).

\section{SWAT modeling}

Data need for the modelling effort include DEM, LULC, soil properties, weather data and observed stream flow data for calibration and validation of the model. The calculation of flow direction, flow accumulation, stream networks, watershed delineation and calculation of sub-basin parameters using SWAT watershed delineator tools requires DEM data. Land use is one of SWAT model's main input data to define the study watershed's hydrological response units (HRU). Soil data, including physical and chemical properties, is an input data for the SWAT model. The weather data used for the study were represented from Five stations in and around the Sore and Geba watershed, such as Alge, Bedele, Gatira, Gore and Metu as shown in (Figure 3). Only Gore station are first class that has records on all climatic variables, whereas the other ones have only precipitation and temperature records. From 01 January 1996 to 31 December 2017, the climate data used for this study cover 21 years. While in some of the climatic variables in all stations, some missing values have been identified. These missing values have been selected and assigned with the SWAT no data value code (-99) that could be filled out from monthly weather generator parameter values embodied in the SWAT model. These monthly weather generator values were estimated by SWAT preprocessing software from Gore Meteorological Station. Data on stream flow is required for model calibration and validation. Because of the availability of daily stream flow data from continuous records from periods (1996-2017) was selected and by calculating the average monthly flows it was prepared according to the required SWAT-CUP format. Finally, as required by the model, all the input data were prepared. 


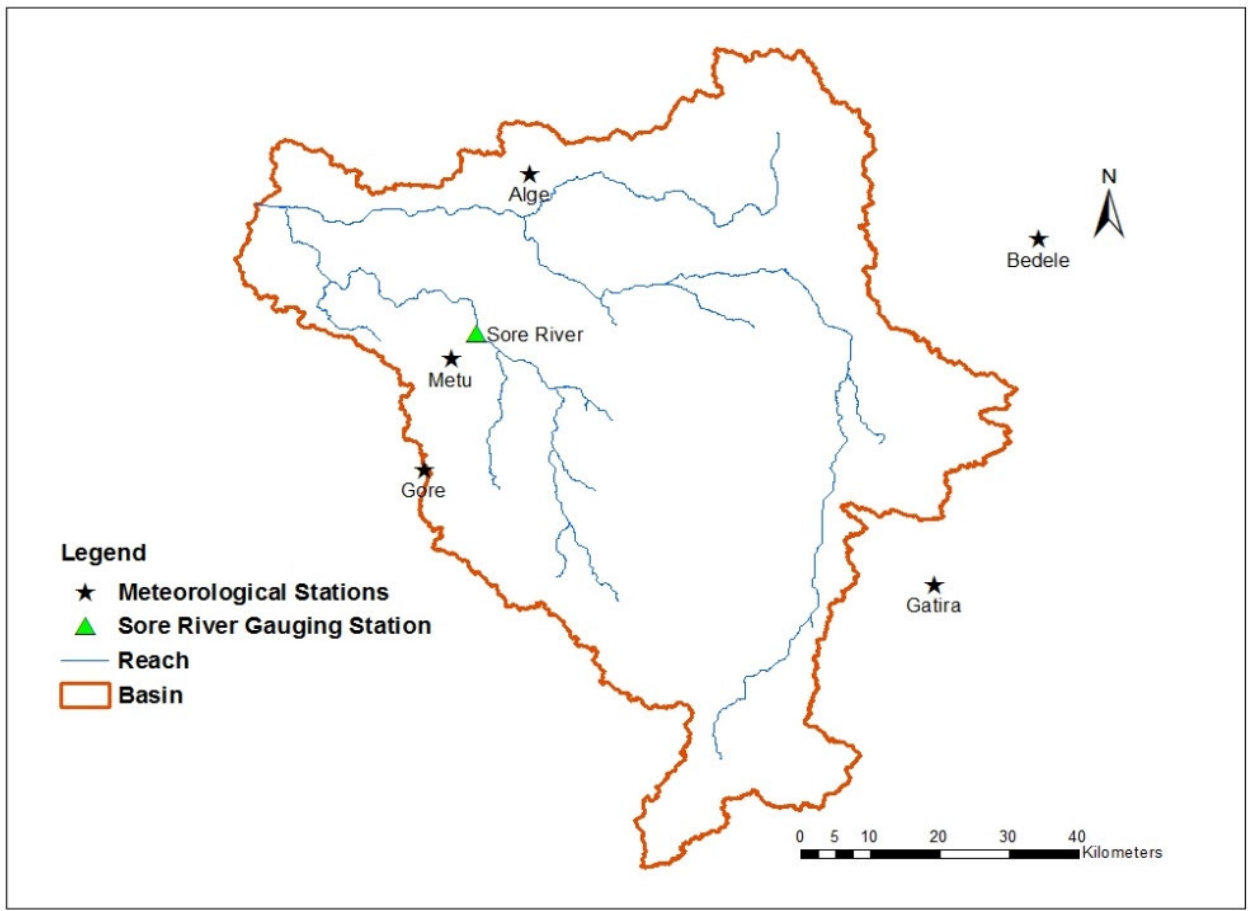

Figure 3. Location map of meteorological stations in and around Sore and Geba watershed

\subsection{Model Setup}

Sore and Geba watershed hydrological modeling was performed using SWAT's ArcSWAT software interface in ArcGIS. It requires basic spatial data such as model of digital elevation, land use and type of soil. SWAT surface runoff simulation is performed using different input data such as land use, topography, soil properties, and basin weather data. The $30 \mathrm{~m}$ by $30 \mathrm{~m}$ resolution Aster Global DEM were obtained from U.S Geological Survey (USGS) website and georeferenced to the projection system of Adindan_UTM_zone_37N. The drainage and flow pattern will be obtained using the DEM, and the stream network will be defined. By selecting the minimum threshold value of drainage area suggested by the Arc SWAT interface (15122.7119 hec), the stream network definition and sub-watershed size were determined. The sore and Geba watershed was delineated in an estimated area of 6551.07 $\mathrm{km}^{2}$ which have 29 sub-watersheds. To define hydrological response unit (HRUs), the model requires data on soil type, land use and slope. For the land use map, $30 \mathrm{~m}$ by $30 \mathrm{~m}$ resolution of Landsat imageries was obtained from the USGS website. After supervised classification in ArcGIS, it was loaded onto the delineated map.

The basin's soil map was clipped from Ethiopia's soil map and overlapped with the delineated area. The DEM data was also used to generate watershed gradient and sub-watershed slope. Subdividing the catchment into areas with unique combinations of land use and soil allows the model to reflect differences in evapotranspiration and other hydrological conditions for different soil and cover (Arnold et al., 2013).

The SWAT user's manual suggested a threshold value of $20 \%$ land use, $10 \%$ soil and $20 \%$ slope combination for most modeling applications to overlay land use, soil and slope using the HRU definition. A research conducted in Ethiopia, however, a threshold value of $10 \%$ land use, $20 \%$ soil and $10 \%$ slope combination was good for better estimation of stream flow (Setegn, 2008). Thus, a threshold of $10 \%$ land use, $20 \%$ soil and $10 \%$ slope combination were used for this study with the HRU definition with multiple options. Therefore, for the land use map of 1987, 2001 and 2017 respectively, the Sore and Geba watersheds were divided into 345, 344 and 300 HRUs, each with a unique combination of soil and land use.

The weather data was formatted into the SWAT weather generator files and accordingly input into the database. The model is then setup and run. Thus, for understanding the effect of land use and land cover change on surface runoff over different time periods, the model was runs by varying the land use map and keeping the other SWAT input parameters constant.

Calibration and validation

SWAT-CUP (SWAT calibration and uncertainty programs) carried out calibration, validation, sensitivity and uncertainty analysis of stream flow parameters for this study. SWAT-CUP is a SWAT model calibration public domain computer program. The program links the Generalized Likelihood Uncertainty Estimate (GLUE), Sequential Uncertainty Fitting, version 2 (SUFI-2), Particle Swarm Optimization (PSO), Parasol Solution (ParaSol) and Markov Chain Monte Carlo (MCMC) to SWAT model output files.(Abbaspour, 2015). For this study, for the monthly SWAT runs, the Sequential Uncertainty Fitting program (SUFI-2) algorithm was used to calibrate Sore 
and Geba watershed (Sore river gauge). The available stream flow data of sore river gauge covered 21years (19962017). The data were split in to two for calibration period (1996-2010) and validation period of (2010-2017).

The expressive flow parameters identifiers were chosen from SWAT database, previous study output and its initial ranges of the parameters used in the calibration were assigned from absolute SWAT values that linked in SWATCUP programs. The sensitive parameters included in the calibration were selected based on an analysis of Global sensitivity that simultaneously varies all parameters. A t-test was then used to identify each parameter's relative significance.

SUFI-2 used 2 iterations, 400 simulations for each iteration on the Sore river gage, and the best simulated parameter values were used for editing the SWAT model. The model was calibrated using the simulated flow obtained from the land use map of the year 1987. Then the best simulated parameter values were used for each land use map (1987, 2001 and 2017) model run. The p-factor quantifies all the uncertainties, which is the percentage of measured data bracketed by the 95PPU (95 percent uncertainty prediction). The quality of the calibration was measured by r-factor, which indicates the thickness of the $95 \%$ prediction uncertainty (95PPU). The validation of the model for stream flow was carried out for the period of (2001-2017) by using the calibrated SWAT-CUP parameters ranges (without any further changes).

\section{Model performance evaluation:}

There are different model performance evaluation techniques such as, Nash-Sutcliffe efficiency (NSE), coefficient of determination $\left(\mathrm{R}^{2}\right)$, percent bias (PBIAS) and by the ratio of the root mean square error of the standard deviation of measured data (RSR) etc. To judge the simulation of streamflow as satisfactory NSE $>0.50, \mathrm{RSR}<0.70$ and PBIAS $+25 \%$ (Moriasi et al., 2007). For this study, the calibration and validation performance were carried out using the $\mathrm{p}$-factor, $\mathrm{r}$-factor, $\mathrm{R}^{2}$ and NS model performance techniques.

\section{Evaluation of LULC change on water balance components}

To evaluate the changes of the simulated water balance components such as, surface runoff influence to river flow, ground water and lateral flow influence to stream flow, actual and potential evapotranspiration due to LULC change, the study was carried out for three different years (1987, 2001 and 2017). In order to evaluate the variability of the water balance components due to LULC changes from 1987 to 2001, 2001 to 2017 and 1987 to 2017, three independent simulation were performed on monthly bases using the 1987, 2001 and 2017 classified land use maps by keeping the other parameters unchanged. Then the outputs from land use map of 1987, 2001 and 2017 was compared.

\section{RESULTS AND DISCUSSION}

\subsection{Land use and land cover analysis}

\subsubsection{Land use and land cover maps}

Using supervised image classification techniques in Sore and Geba watershed five main land use types have been identified such as cultivated land, dense forest, open forest, woodland and water bodies. The 1987, 2001 and 2017 land use map generated from Landsat-5-TM, Landsat-7-ETM+ and Landsat 8 image classification respectively was shown in Figure 4 blow. In the last 30 years (1987-2017), there has been an upsurge in cultivated land and a decrease in dense forest, open forest, woodland and water bodies in the watershed of Sore and Geba. The total area coverage of the cultivated land in 1987 was around $33 \%$ and in 2001 about $34 \%$ of the total area of the watershed, but in 2017 it increased rapidly to 50\%. This is because of the gain of land from the shrinkage of other types of land use due to population growth and deforestation. For example, the total area coverage of dense forest, open forest, wood land, and water bodies in 1987 LULC maps was about 3\%, 49\%, 4\% and 11\% respectively. However, in 2017 land use and land cover map it decreased to around $0 \%, 44 \%, 1 \%$ and 5\% of Sore and Geba watershed area. The individual area coverage and change statistics for the three periods 1987 to 2001, 2001 to 2017 and 1987 to 2017 are summarized in (Table 2). The results revealed from this study is consistent with the results of previous study in different parts of Ethiopia(Wubie, 2015; Bewket and Abebe, 2013). 


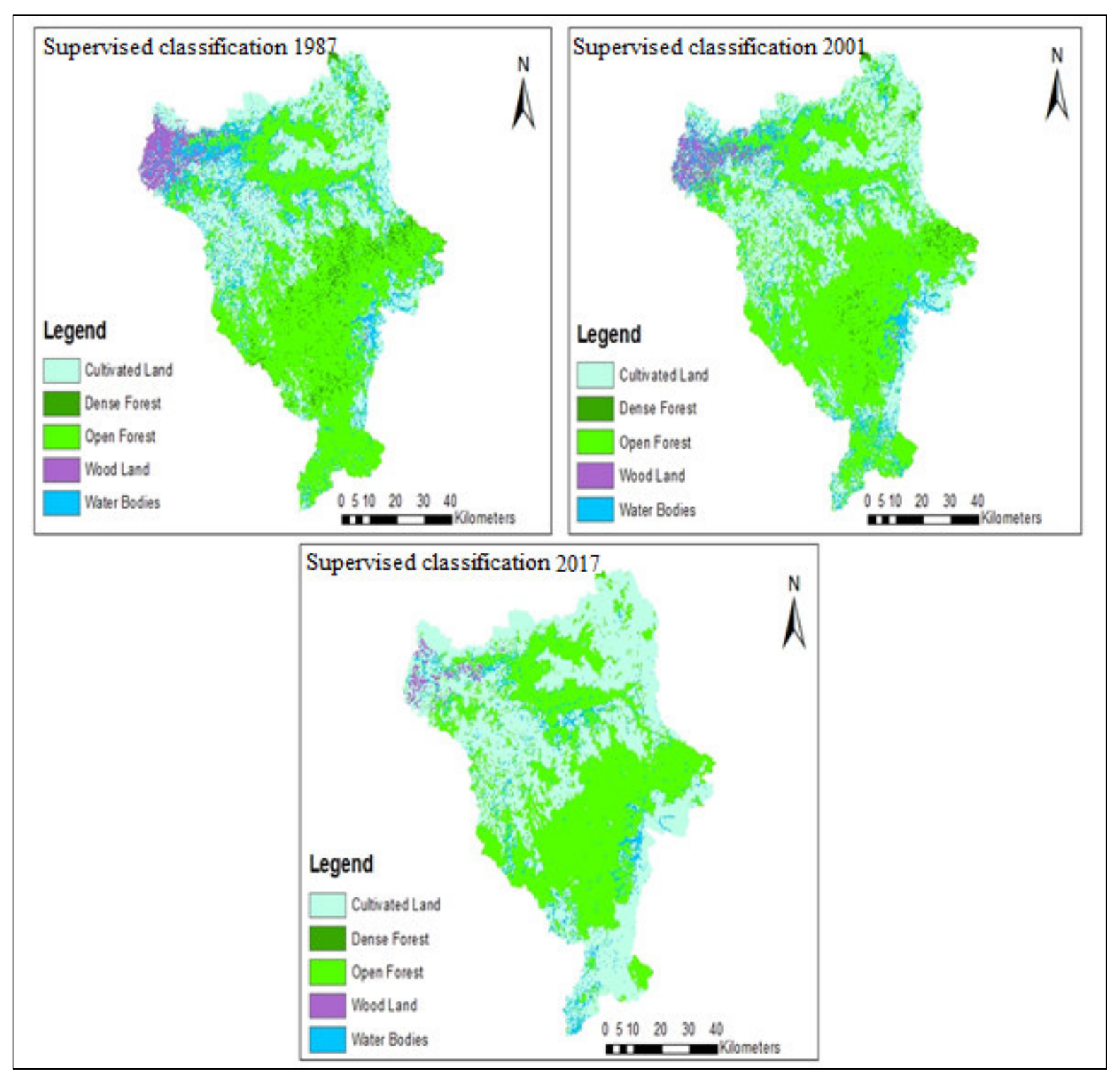

Figure 4. Land cover map of Sore and Geba watershed in 1987, 2001 and 2017

Table 2. Type of land use and change statistics for the 1987,2001 and 2017 Sore and Geba watershed

\begin{tabular}{|c|c|c|c|c|c|c|c|c|c|c|c|c|}
\hline \multirow[t]{2}{*}{ Land use types } & \multicolumn{2}{|l|}{1987} & \multicolumn{2}{|l|}{2001} & \multicolumn{2}{|l|}{2017} & \multicolumn{2}{|c|}{ 2001-1987 } & \multicolumn{2}{|c|}{ 2001-2017 } & \multicolumn{2}{|c|}{ 1987-2017 } \\
\hline & $\mathrm{km}^{2}$ & $\%$ & $\mathrm{~km}^{2}$ & $\%$ & $\mathrm{~km}^{2}$ & $\%$ & $\mathrm{~km}^{2}$ & $\%$ & $\mathrm{~km}^{2}$ & $\%$ & $\mathrm{~km}^{2}$ & $\%$ \\
\hline Cultivated Land & 2161.20 & 32.99 & 2240.62 & 34.20 & 3245.66 & 49.54 & 79.42 & 1.21 & 1005.04 & 15.34 & 1084.46 & 16.55 \\
\hline Dense Forest & 222.04 & 3.39 & 84.52 & 1.29 & 4.14 & 0.06 & -137.52 & -2.10 & -80.38 & -1.23 & -217.90 & -3.33 \\
\hline Open Forest & 3231.68 & 49.33 & 3447.04 & 52.62 & 2887.37 & 44.08 & 215.36 & 3.29 & -559.66 & -8.54 & -344.30 & -5.25 \\
\hline Wood Land & 235.27 & 3.59 & 169.35 & 2.59 & 70.96 & 1.08 & -65.92 & -1.00 & -98.39 & -1.50 & -164.31 & -2.51 \\
\hline Water Bodies & 700.88 & 10.70 & 609.54 & 9.30 & 342.94 & 5.24 & -91.35 & -1.40 & -266.60 & -4.07 & -357.94 & -5.46 \\
\hline
\end{tabular}

\subsubsection{Evaluation of accuracy}

To evaluate the correctness of the classified image, the accuracy assessment is used. For this study confusion matrix was used. Using google earth image as a reference and the original mosaic satellite image, there were randomly selected reference points for each land cover types. With the corresponding classified map, the randomly selected points were compared. For the validation of the 1987, 2001 and 2017 images, 82, 85 and 108 points were selected. Using the confusion matrix, the overall accuracy, the accuracy of the producer and the accuracy of Landsat images of 1987, 2001 and 2017 were calculated.

The results of the confusion matrix for the 1987, 2001 and 2017 maps were $89 \%, 95.3 \%$ and $96.3 \%$ respectively. The most accurate map is 2017 which is the latest product of Landsat 8 satellite image. The minimum value suggested by Anderson (1976) for overall accuracy is $85 \%$. Therefore, for all land cover maps, the 
classification conducted for this study produces an overall accuracy that meets the minimum value suggested by Anderson (1976).

The producer's accuracy results for land use map of 1987, 2001 and 2017 ranges from $60 \%$ to $100 \%, 72.7 \%$ to $100 \%$ and $63.6 \%$ to $100 \%$ respectively. Whereas, the user's accuracy ranges from $75 \%$ to $96.7 \%, 85.7 \%$ to $100 \%$ and $88.9 \%$ to $100 \%$ respectively. Due to the spectral similarity of different land uses, the lowest values were misclassified.

The accuracy assessment results from the Kappa coefficient statistics $\widehat{(K)}$ is $0.85,0.94$ and 0.95 for the period of 1987, 2001 and 2017 respectively. For the period 1987, a kappa of 0.85 means that agreement is 85 percent better than by chance alone. Kappa of 0.94 for the period of 2001 means $94 \%$ better agreement than by chance alone. And there is $95 \%$ better agreement for the 2017 period than by chance alone.

\subsection{Calibration and Validation}

The model was calibrated using a sequential uncertainty fitting (SUFI-2) algorithm using the SWAT-CUP computer program. The model was evaluated using Determination Coefficient $\left(\mathrm{R}^{2}\right)$ and Nash-Sutcliffe efficiency (NS) values for fit measurement goodness. The value of R2 ranges from 0 meaning poor model performance to 1 showing good performance, and the value of NS ranges from negative infinity to 1 . The larger the value of $\mathrm{R}^{2}$ and NS the better the agreement between measured and simulated flows. The other model prediction uncertainty measures selected for this study was p-factor and r-factor. The p-factor value ranges from 0 to $100 \%$, while the $\mathrm{r}$ factor value ranges from 0 to an infinity. A threshold value suggested by (Abbaspour, 2015) >70\% of p-factor and having $r$-factor of around 1 is recommended for a better result of calibration of a model by SWAT-CUP. The $p$ factor shows the percentage of measured data bracketed by the predictive uncertainty of 95 percent (95PPU) and provides the capability of the models to capture uncertainties. The r-factor shows the 95PPU thickness and is a measure of calibration quality.

The model was calibrated for Sore and Geba watershed with Sore river gauging station. Figure 5 shows the five-year (2005-2010) calibration and (2011-2016) validation periods of measured and simulated monthly stream flows for the Sore and Geba watershed at the Sore river. The SWAT model accurately tracked the lowest observed stream flows but some of the highest observed flows in the first year of simulation was over predicted for both calibration and validation period. However, the simulated flows in calibration period is closely followed the observed flows than the validation period. The model performance measures statistics during calibration were stronger than those computed for validation period. According to a threshold values suggested by different scholars the computed statistics for Sore and Geba watershed showed satisfactory result for both calibration and validation periods. For example, p-factor 0.78 , r-factor 1.02, determination coefficient (R2) 0.8 and Nash-Sutcliffe efficiency (NS) 0.79 during the calibration period, where p-factor 0.78 , r-factor 1.26 , determination coefficient (R2) 0.75 and Nash-Sutcliffe efficiency (NS) 0.54 are used for the monthly data simulation. The statistics generally show that there is a strong correlation between the values simulated and measured.

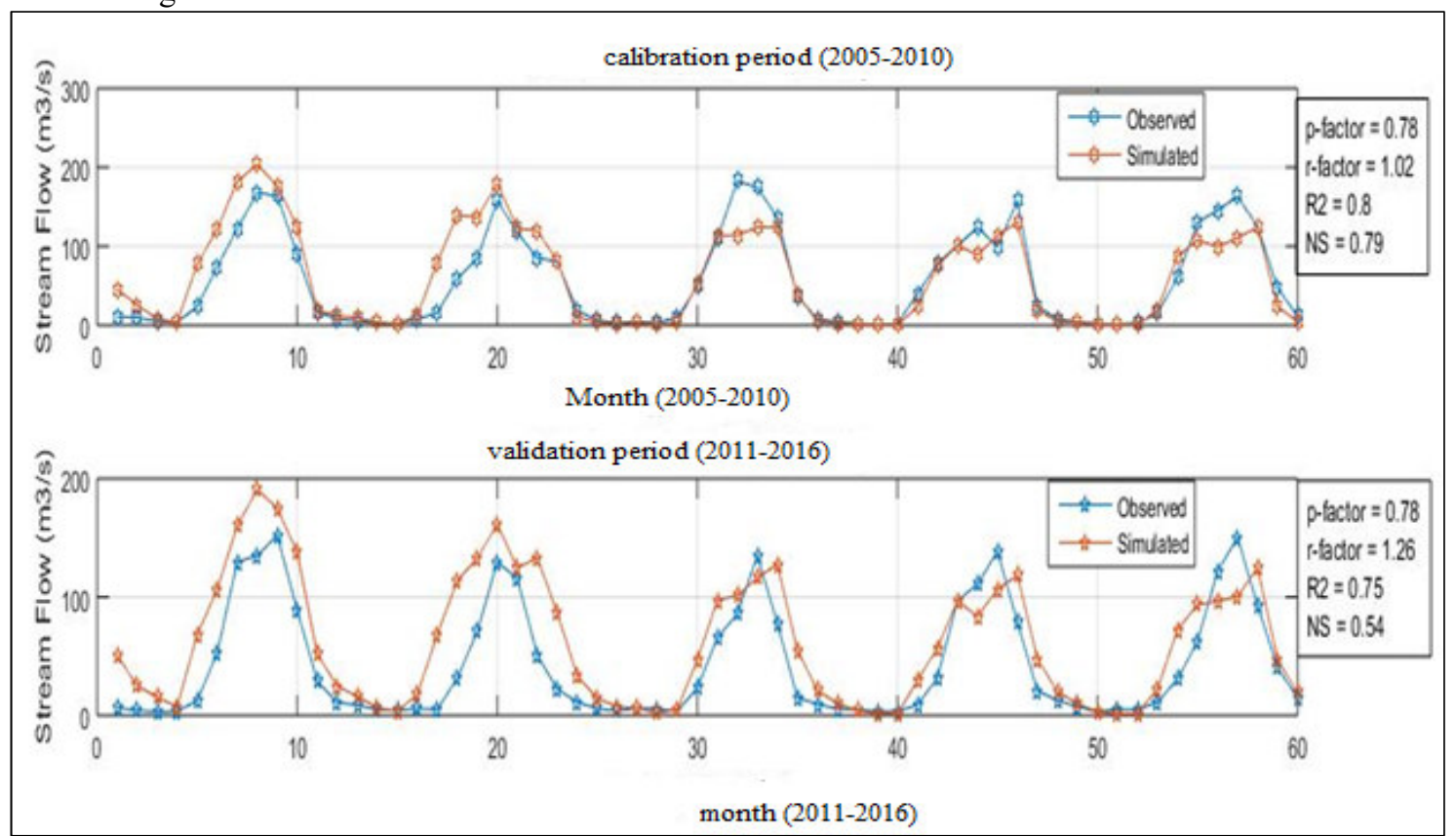

Figure 5. Time series plot of observed and simulated stream flow for calibration and validation period at sore river gauge station 
As shown in Table 3, the simulated average monthly stream flow at Sore river gage for both calibration and validation periods were pretty much close to observed flows with the agreement slightly is better in calibration period. Overall, the model performance was good.

Table 3. Comparison of observed and simulated average monthly stream flow at Sore river gauging station for calibration and validation.

\begin{tabular}{|c|c|c|c|c|c|c|}
\hline \multirow[t]{2}{*}{ Period } & \multicolumn{2}{|c|}{ Average Monthly Flow $\left(\mathrm{m}^{3} / \mathrm{s}\right)$} & \multirow[t]{2}{*}{ p-factor } & \multirow[t]{2}{*}{ r-factor } & \multirow[t]{2}{*}{$\mathrm{R}^{2}$} & \multirow[t]{2}{*}{ NS } \\
\hline & Measured & Simulated & & & & \\
\hline Calibration (2005-2010) & 56.75 & 60.47 & 0.78 & 1.02 & 0.8 & 0.79 \\
\hline Validation (2011-2016) & 43.12 & 61.34 & 0.78 & 1.26 & 0.75 & 0.54 \\
\hline
\end{tabular}

The study conducted by Mengistu and Sorteberg (2012) in the Baro-Akobo river basin to calibrate and validate the monthly streamflow simulation at the Gambela gauge station gives Nash-Sutcliffe efficiency (NS) 0.9 and Determination Coefficient (R2) 0.92 for the calibration period and 0.81 and 0.89 for the validation period.

\subsection{LULC change effect on surface runoff}

The impact of LULC changes on surface runoff is derived from the comparison of the model output from the 1987, 2001 and 2017 land use and cover maps. By considering the 1987 LULC map as a baseline scenario the changes of average annual surface runoff during the periods of 1987 to 2001, 2001 to 2017 and 1987 to 2017 are calculated using simple change statistics formula (Table 4). The annual simulated amount of surface runoff contribution to stream flow from land use map of 1987, 2001 and 2015 are $39.32 \mathrm{~m}^{3} / \mathrm{s}(189.28 \mathrm{~mm}), 39.78 \mathrm{~m}^{3} / \mathrm{s}(191.52 \mathrm{~mm})$ and $45.95 \mathrm{~m}^{3} / \mathrm{s}(221.19 \mathrm{~mm})$ respectively. The average annual contribution of surface runoff to stream flow increased between the periods of 1987 and 2001 from $39.32 \mathrm{~m} 3 / \mathrm{s}$ to $39.78 \mathrm{~m} 3 / \mathrm{s}$ due to the LULC change (increased by $1.18 \%$ ). The land use change occurred between the periods of 2001 and 2017 leads to increase the surface runoff from $39.78 \mathrm{~m}^{3} / \mathrm{s}$ to $45.95 \mathrm{~m}^{3} / \mathrm{s}$ (which is increased by $15.49 \%$ ). Whereas, during the period of 1987 and 2017 land use land cover change the surface runoff contribution to stream flow increased from $39.32 \mathrm{~m}^{3} / \mathrm{s}$ to $45.95 \mathrm{~m}^{3} / \mathrm{s}$ (which is increased by $16.86 \%$ ).

The average monthly and annual contribution of surface runoff to stream flow during the periods of 1987 and 2001 land use and land cover change doesn't show significant change. However, during the periods of 2001 and 2017 the surface runoff is rapidly increased by $15.49 \%$. This is due to the expansion of cultivated land over dense and open forest between 2001 and 2017, resulting in increased surface runoff following events of rainfall. The increments of cultivated land in between the periods of 1987 and 2001 is $1.21 \%$ while between the periods of 2001 and 2017 the cultivated land increased by $15.34 \%$. The higher increment of surface runoff in between the periods of 2001 and 2017 in Sore and Geba watershed is strongly related to the expansion of cultivated land.

Table 4. Average annual surface runoff basin values change statistics for the period of 1987, $2001 \& 2017$

\begin{tabular}{|l|l|l|l|l|l|l|l|l|l|}
\hline Year & $\mathbf{1 9 8 7}$ & $\mathbf{2 0 0 1}$ & $\mathbf{2 0 1 5}$ & $\mathbf{2 0 0 1 - 1 9 8 7}$ & \multicolumn{2}{|l|}{$\mathbf{2 0 0 1 - 2 0 1 7}$} & \multicolumn{1}{|c|}{$\mathbf{1 9 8 7 - 2 0 1 7}$} \\
\hline Unit & $\mathrm{mm}$ & $\mathrm{mm}$ & $\mathrm{mm}$ & $\mathrm{mm}$ & $\%$ & $\mathrm{~mm}$ & $\%$ & $\mathrm{~mm}$ & $\%$ \\
\hline Surface runoff & 189.28 & 191.52 & 221.19 & 2.24 & 1.18 & 29.67 & 15.49 & 31.91 & 16.86 \\
\hline
\end{tabular}

\subsubsection{Implication of changes in land use on stream flow}

To realize the implication of LULC change on stream flow in Sore and Geba watershed the stream flow obtained from the whole watershed were used that simulated from (2005-2010) using land use map of 1987, 2001 and 2017. The highest mean monthly stream flow simulated using land use map of 1987 occurred in August which is equal to $499.70 \mathrm{~m}^{3} / \mathrm{s}$ and the minimum stream flow occurred in March which is $7.73 \mathrm{~m}^{3} / \mathrm{s}$. From land use map of 2001 the simulated highest mean monthly stream flow is occurred in August which is equal to $499.73 \mathrm{~m}^{3} / \mathrm{s}$ and the minimum stream flow is $8.31 \mathrm{~m}^{3} / \mathrm{s}$ which is occurred in March. The highest mean monthly streamflow simulated using land use map of 2017 occurred in August which is equal to $501.42 \mathrm{~m}^{3} / \mathrm{s}$ while the minimum flow occurred in February and equal to $10.05 \mathrm{~m}^{3} / \mathrm{s}$. The average annual stream flow simulated using the 1987, 2001 and 2017 land use map is $188.06 \mathrm{m3} / \mathrm{s}, 187.92 \mathrm{m3} / \mathrm{s}$, and $190.84 \mathrm{~m}^{3} / \mathrm{s}$ respectively. The highest mean annual stream flow is obtained from the simulated result of land use map of 2017. This is because of the highest cultivated land in 2017 than 2001 and 1987. The mean annual stream flow obtained from land use map of 2001 is lower than 2017 and 1987 because of the highest area coverage of open forest. Due to land use and land cover change between 1987 and 2017, the stream flow is increased by $2.78 \mathrm{~m} 3 / \mathrm{s}$. In general, within the periods of 1987 and 2001 there is no significant change on stream flow because of the similarity of area coverage of land use types.

\subsubsection{Environmental implication of the observed surface runoff}

The change of LULC has made a substantial consequence on the hydrology including surface runoff, stream flow, evapotranspiration, sediment loading and water yield of the study watershed. Vegetation cover helps to reduce the soil erosion by interrupting and dissipating the erosive power of rainfall, runoff and wind. It has also a role in reducing the volume of runoff through increasing the infiltration by following the root system and increases soil organic content which increase the aggregate stability of the soil. Within the study period there has been a decline of natural forests and expansion of agricultural lands. As can be quantified in this study the expansion of agricultural lands generates highest surface runoff. This highest surface runoff will accelerate the erosion process 
such as detachment and transportation. Sediment loading was also highest due to the expansion of agricultural lands. All this phenomenon has an implication on the environment such as biodiversity loss, flooding and sedimentation on the downstream water storage structures.

\section{CONCLUSION}

LULC trend analysis within the periods of three decades from 1987 to 2017 in Sore and Geba watershed shows a significant change over the years. The area coverage of cultivated land, open forest, dense forest, wood land, and water bodies of Sore and Geba watershed in 1987 were $33 \%, 49 \%, 3 \%, 4 \%$ and $11 \%$ of the total watershed, respectively. Whereas, in 2017 open forest, dense forest, wood land and water bodies diminished to $44 \%, 0 \%, 1 \%$ and $5 \%$ of the total watershed respectively. Whereas the coverage of cultivated land increased to $50 \%$ of the total watershed. Cultivated land is gained from other types of land use. In the last three decades there has been an increase in scattered rural settlements closely associated with cultivated land. Due to deforestation, the highest land use and land cover change occurred between 2001 and 2017.

In the study watershed, nine sensitive flow control parameters were identified using SWAT-CUP computer program by SUFI-2 algorithm that were targets of the calibration process. During the calibration period, values of Nash-Sutcliffe (NS), coefficient of determination $\left(\mathrm{R}^{2}\right)$, p-factor and $\mathrm{r}$-factor were $0.79,0.8,0.78$ and 1.02 respectively. Whereas for the validation period the values were $0.54,0.75,0.78$ and 1.26 respectively. For both calibration and validation period, this performance is viewed satisfactory. The effects of land use and land cover change on surface runoff and stream flow were evaluated after calibration and validation of the SWAT model. The observed LULC change shows a significant change on the hydrological process in the watershed particularly surface runoff, stream flow, evapotranspiration, and groundwater flow. The simulated average annual surface runoff from LULC map of 1987 was $189.28 \mathrm{~mm}$ while from land use map of 2017 the average annual surface runoff increased to $221.19 \mathrm{~mm}$. This result showed that during the last three decades (1987-2017) LULC change indicated an increase of surface runoff by $16.86 \%$. The average annual stream flow increased from $188.06 \mathrm{~m}^{3} / \mathrm{s}$ to $190.84 \mathrm{~m}^{3} / \mathrm{s}$ between the periods of 1987 and 2017 LULC change. The quantified LULC change and surface runoff has an implication on the environment, such as loss of biodiversity, loss of top soil by erosion, flooding and sedimentation problems in the downstream communities. This study suggests promoting non-timber forest products, planning and regulating the expansion of settlements and soil fertility management activities should be implemented. This would increase existing farming productivity and help in controlling the expansion of cultivated land. Finally, this study highlights the application of SWAT model integrated with GIS tools in the study basin provides a better understanding of the process of impacts of land use change in local hydrology.

\section{References}

Abbaspour, K. C. (2015). SWAT - CUP SWAT Calibration and Uncertainty Programs-A User Manual. Eawag (Swiss Federal Institute of Aquatic Science and Technology).

Alemayehu, T. (2016). Groundwater Recharge under Changing Landuses and Climate Variability: The Case of Baro-Akobo River Basin , Ethiopia. Journal of Environment and Earth Science, 6(1), 78-95.

Anderson, B. J. R., Hardy, E. E., Roach, J. T., \& Witmer, R. E. (1976). A Land Use And Land Cover Classification System For Use With Remote Sensor Data. Geological Survey Professional Paper 964.

Arnold, J. G., Kiniry, J. R., Srinivasan, R., Williams, J. R., Haney, E. B., \& Neitsch, S. L. (2013). Soil \& Water Assessment Tool: Input/output documentation. version 2012. Texas Water Resources Institute, TR-439, 650.

Bao-qi Li, Wei-hua Xiao, Yi-cheng Wang, Ming-zhi Yang, Ya Huang (2018). Impact of land use/cover change on the relationship between precipitation and runoff in typical area. Journal of Water and Climate Change; Vol. 9 (2): 261-274.

Bewket, W., \& Abebe, S. (2013). Land-use and land-cover change and its environmental implications in a tropical highland watershed, Ethiopia. International Journal of Environmental Studies, 70(1), 126-139.

Beyene, S.K. \& Kemal, A \& Pingale, Dr. Santosh. (2018). Impact of Land Use/Land Cover Change on Watershed Hydrology: A Case Study of Upper Awash Basin, Ethiopia. Ethiopian Journal of Water Science and Technology (EJWST). 1. 4-27.

Birhanu A. \& Masih I. Nyssen Jan, van der Zaag, Pieter Cai, Xueliang. (2019). Impacts of land use and land cover changes on hydrology of the Gumara catchment, Ethiopia. Physics and Chemistry of the Earth, Parts A/B/C.

Devi, G. K., Ganasri, B. P., \& Dwarakish, G. S. (2015). A Review on Hydrological Models. Elsevier B.V., 4(Icwrcoe), 1001-1007.

Ebrahim H. \& Mohamed A. (2018). Land use/cover dynamics and its drivers in Gelda catchment, Lake Tana watershed, Ethiopia. Environmental Systems Research. 6. 10.1186/s40068-017-0081-x.

Emnet N., Girmay G/Samuel, Tesfa-alem E. \& Amanuel A (2019). The effect of climate and land-cover changes on runoff response in Guguf spate systems, northern Ethiopia. Irrigation and Drainage. 10.1002/ird.2326.

Gessesse, B., Bewket, W., \& Bräuning, A. (2014). Model-Based Characterization and Monitoring of Runoff and Soil Erosion in Response To Land Use / Land Cover Changes in the Modjo Watershed , Ethiopia, 
724(February 2014), 711-724.

Getahun, Y. S., \& Haj, V. L. (2015). Assessing the Impacts of Land Use-Cover Change on Hydrology of Melka Kuntrie Subbasin in Ethiopia, Using a Conceptual Hydrological Model, 6(3). https://doi.org/10.4172/21577587.1000210

Guo, H., Hu, Q., \& Jiang, T. (2008). Annual and seasonal streamflow responses to climate and land-cover changes in the Poyang Lake basin, China. Journal of Hydrology, 355(1-4), 106-122.

Hasmadi, M., Hz, P., \& Mf, S. (2009). Evaluating supervised and unsupervised techniques for land cover mapping using remote sensing data, $1(1), 1-10$.

Kassa, H., Dondeyne, S., Poesen, J., Frankl, A., \& Nyssen, J. (2016). Transition from forest- to cereal-based agricultural systems : a review of the drivers of land-use change and degradation in southwest Ethiopia. Land Degradation \& Development, in press.

Lindquist, erik J., D’annunzio, R., Gerrand, A., Macdicken, K., Achard, F., Beuchle, R., ... Stibig, H.-J. (2012). Global forest land-use change 1990-2005, food and agriculture organization of the united nations Rome.

Mengistu, D. T., \& Sorteberg, A. (2012). Sensitivity of SWAT simulated streamflow to climatic changes within the Eastern Nile River basin, 391-407.

Moriasi, D. N., Arnold, J. G., Liew, M. W. Van, Bingner, R. L., Harmel, R. D., \& Veith, T. L. (2007). Model evaluation guidelines for systematic quantification of accuracy in watershed simulations, 50(3), 885-900.

Neitsch, S.L., Arnold, J.G., Kiniry, J. R., Williams, J.R. (2011). Soil \& Water Assessment Tool Theoretical Documentation Version 2009.

Nguyen Cung Que T., Nguyen H., \& Kondoh A. (2018). Land Use and Land Cover Changes and Their Effect on the Flow Regime in the Upstream Dong Nai River Basin, Vietnam. Water. 10. 1206. 10.3390/w10091206.

Olofsson, P., Foody, G. M., Herold, M., Stehman, S. V, Woodcock, C. E., \& Wulder, M. A. (2014). Remote Sensing of Environment Good practices for estimating area and assessing accuracy of land change. Remote Sensing of Environment, 148, 42-57.

Sajikumar, N., \& Remya, R. S. (2015). Impact of land cover and land use change on runoff characteristics. Journal of Environmental Management, 161, 460-468.

Setegn, S. G. (2008). Hydrological and sediment yield modelling in lake tana basin, Blue Nile Ethiopia. Licentiate thesis KTH-Hydraulic Engineering Research Group Department of Land and Water Resources Engineering Royal Institute of Technology (KTH) SE-100 44 Stockholm, Sweden.

Tekalegn A. (2017). Assessing Impacts of Land Use/Cover and Climate Changes on Hydrological Regime in the Headwater Region of the Upper Blue Nile River Basin, Ethiopia

Tilahun, A. K. (2015). Land use land cover change and its implication on surface runoff : A Case Study of Baro River Basin in South Western Ethiopia, 5(8), 53-58.

Woube, M. (1999). Flooding and sustainable land-water management in the lower Baro-Akobo river basin, Ethiopia. Applied Geography, 19(3), 235-251.

Wubie, A. M. (2015). GIS and remote sensing based forest change detection for sustainable forest management in Bench Maji Zone, Ethiopia. International Journal of Remote Sensing \& Geoscience (IJRSG).

Zhang, L., Nan, Z., Xu, Y., \& Li, S. (2016). Hydrological Impacts of Land Use Change and Climate Variability in the Headwater Region of the Heihe River Basin, Northwest China. PloS one, 11(6), e0158394. doi:10.1371/journal.pone.0158394. 